\title{
APBioNet's annual International Conference on Bioinformatics (InCoB) returns to India in 2018
}

\author{
Shandar Ahmad', Michael M. Gromiha², Gajendra P. S. Raghava ${ }^{3}$, Christian Schönbach ${ }^{4,5}$ and Shoba Ranganathan ${ }^{6,7^{*}}$
}

\begin{abstract}
InCoB, one of the largest annual bioinformatics conferences in the Asia-Pacific region since its launch in 2002, returned to New Delhi, India after 12 years, with a conference attendance of 314 delegates. The 2018 conference had sessions on Big Data and Algorithms, Next Generation Sequencing and Omics Science, Structure, Function and Interactions, Disease and Drug Discovery and Plant and Agricultural Bioinformatics. The conference also featured an industry track as well as panel discussions on Women in Bioinformatics and Democratization vs. Quality control in academic publishing. Asia Pacific Bioinformatics Interaction \& Networking Society (APbians) was launched as an APBionet Special Interest Group. Of the 52 oral presentations made, 22 were accepted in supplemental issues of BMC Bioinformatics, BMC Genomics or BMC Medical Genomics and are briefly reviewed here. Next year's InCoB will be held in Jakarta, Indonesia from September 10-12, 2019.
\end{abstract}

Keywords: InCoB, International conference on bioinformatics, APBioNet, Asia-Pacific bioinformatics network, APbians

\section{Introduction}

The International Conference on Bioinformatics (InCoB) was held for the first time in New Delhi, India in 2006 and returned in September 26-28, 2018 [1], with over 310 delegates. The Vice Chancellor of Jawaharlal Nehru University delivered the inaugural address. Three parallel sessions accommodated 24 sessions of 52 oral presentations while two evening sessions featured 154 poster presentations.

Fifteen keynote and invited talks addressed the current advances in genomics, transcriptomics, systems biology, protein structure and interactions, drug discovery, oncology and precision medicine. Three special sessions included an industry session with a presentation by Schrodinger Inc. and two panel discussions on Women in Bioinformatics and on Democratization vs. Quality control in academic publishing. At the Annual General Meeting of APBioNet on September 27, Christian Schönbach delivered the President's Report on the state of APBioNet and its activities in the past year. The AGM was concluded with the

\footnotetext{
* Correspondence: shoba.ranganathan@mq.edu.au

${ }^{6}$ Department of Molecular Sciences, Macquarie University, Sydney, NSW 2109, Australia

${ }^{7}$ Transformational Bioinformatics, Health and Biosecurity, Commonwealth

Scientific and Industrial Research Organisation, Sydney, Australia

Full list of author information is available at the end of the article
}

announcement of election results for the Executive Committee (ExCo), term 2018-2020, by the returning officer. The list of elected ExCo members and office bearers is available at the APBioNet website [2].

\section{Manuscript submission and review}

For the first time, submissions were handled directly on the Springer Nature Editorial Manager system. Authors submitted initial manuscripts on original research or software and database articles, for consideration to BMC editors to nominate one of four BMC journals for submission of: BMC Genomics, BMC Bioinformatics, BMC Systems Biology or BMC Medical Genomics. Selected manuscripts were then sent for peer review by the InCoB2018 Program Committee members. 95\% of the manuscripts sent for review were accepted after an average of 2 rounds of revision. Twenty-seven manuscripts were published in the InCoB2018 supplements of BMC Medical Genomics (2), BMC Genomics (6), BMC Bioinformatics (19) issues.

\section{Knowledge extraction}

Extracting knowledge from large data collections, such as biological Big Data, has dominated bioinformatics endeavours in the past few years. With the focus on novel drug 
discovery, Lynn and his group have developed a Galaxy server to build a predictive model for QSAR-based virtual screening of small molecules [3], while Zheng at al. [4] have developed system to predict the side effects of approved drugs, based on negative samples. Pritam et al. [5] have identified epitope candidate against malaria based on a genome-wide immunoinformatics approach. Text-mining approaches have been used to mine published literature with BioReader [6] while Dhillon and co-workers have efficient setup clinical data management systems for breast cancer from electronic medical records [7]. Abu and coworkers [8] have developed an automated facial recognition system, using a minimal 3D feature set.

\section{Sequence analysis}

With several large-scale genome sequencing projects of non-model organisms underway, the accuracy of the genome cannot be easily assessed, in the absence of a reference genome. For such projects, SQUAT [9] provides a rapid tool to evaluate de novo assemblies, rapidly identifying regions that are poorly mapped or require improvement. In the case of genome annotation, genes encoding small open reading frames are frequently missed. Mat-Sharani and Firdaus-Raih [10] have developed a generic annotation workflow for targeting these elusive regions and applied it successfully to a massive dataset of 31 fungal genomes.

Several novel methods for predicting sites involved in sumoylation [11], phosphoglyceration [12], glycation [13] and lysine glutarylation [14] from sequence data add valuable approaches to functional annotation of proteins. Since protein function is derived from structure, the functional characterization of intrinsically disordered proteins has remained difficult. Sharma et al. [15] have developed an excellent a support-vector machine (SVM) based approach, to identify functionally significant parts of such proteins, such as those involved in molecular recognition processes.

DNA methylation is a key epigenetic mechanism of genomic regulation. Large-scale epigenome analysis is critical for discovering novel therapeutic and prognostic biomarkers. Pappalardo and co-workers present EpiMethX [16] for such analysis, for discovering methylation hotspots, important for cancer progression. In ecological samples, on the other hand, there are multiple viral genomes, to be identified concurrently. To address this problem, Halgamuge and coworkers have developed a novel method, ENVirT [17] which is several orders of magnitude more accurate than other available methods.

\section{Transcriptome analysis}

For clinical relevance, disease gene biomarkers need to be sub-type specific. Hsu et al. [18] have analysed gene expression profiles for two different types of glioma and determined subtype-specific candidate biomarkers relevant to survival. Raghava and his group have developed a carefully curated database for chromosomal fragile sites in the human genome, HumCFS [19], as a resource for genome instability analysis, relevant to cancers and neurological conditions.

MicroRNAs (miRNAs) are functionally important for gene regulation. Guo et al. [20] have sequenced miRNAs from an economic and horticulturally important plant, Rosa rugosa and report the functional enrichment miRNA profiles of leaves and petals.

In a pharmacogenomic approach, Taguchi [21] has analysed gene expression profiles of cells treated with different drugs to identify two pan-cancer candidate drugs, using a tensor decomposition-based unsupervised feature extraction approach.

\section{Structural bioinformatics}

Changes in chromatin structures are associated with diseases, such as aggressive cancers. However, there is paucity of studies on 3D chromatin structure. Nagai et al. [22] report a complex relationship between chromatin reorganization at the structural level and gene regulation, with implications for cancer development.

Protein function is dependent on its 3D structure. Bioinformatics provides solutions to predicting the 3D structures of proteins that so not have experimental structures. Hardianto et al. [23] have used homology models of novel protein kinase $\mathrm{C}$ (PKC) isozymes to characterize their interaction with a candidate inhibitory drug molecule. On the other hand, Borah and Jha [24] have predicted an ab initio structural model for a pathogenic protein, HopS2, that affects tomato plants, to understand its pathogenic function, as a Type III secretion system.

For peptide-based therapeutics, it is important to know their exact binding sites on target proteins, using proteinpeptide docking. As the majority of computational docking methods have been developed for drug-protein interactions, Agarwal et al. [25] have carried out extensive benchmarking of six most commonly used methods for a large number of protein-peptide combinations. They report that FRODOCK performed best in case of blind docking and ZDOCK in case of re-docking.

\section{Network analysis}

Biological molecules interact and communicate with each other and such interactions are represented by networks. While this approach has led to several network representations of experimental data, some information is invariably missed. In order to detect hidden interactions, Elati and co-workers [26] have proposed a latent network approach for large-scale gene expression datasets, presenting impressive results on bladder cancer datasets. 
Manoj et al. [27] have analysed gene expression patterns sugarcane to identify genes that can withstand the effects of climate change and report specific genes which confer drought resistance and tolerance to salinity.

Sen et al. [28] have analysed structural networks to uncover the evolutionary changes in cancer relevant proteins. Kaalia and Rajapakse [29] have extended protein interaction networks to the entire human proteome and report enrichment of gene sets of known functions.

\section{Conclusion}

With the growing interest in applying bioinformatics to personalized and precision medicine, $\mathrm{InCoB}$ is becoming increasingly important to the medical community and the 2019 conference will be hosted by Yarsi University in Jakarta, Indonesia, from Sept. 10-12, 2019.

\section{Acknowledgements}

We are extremely grateful the Department of Biotechnology (DBT) Government of India for their continued support and the Department of Science and Technology (DST), India for a DST-PURSE-II award. We thank the International Society of Computational Biology (ISCB), the Pathfinder Research and Training Foundation, New Delhi, AgriGenome and Schrödinger Inc. for their support.

We thank all the reviewers for their time and effort. We are grateful the excellent support by staff of the APBioNet Secretariat and the School of Computational and Integrative Sciences, Jawaharlal Nehru University.

\section{Funding}

Publication costs for this article were funded by InCoB 2018.

\section{Availability of data and materials}

Not applicable.

\section{About this supplement \\ This article has been published as part of the 17th International Conference on Bioinformatics (InCoB2018): Medical Genomics/Genomics/Bioinformatics, from the 17th International Conference on Bioinformatics (InCoB2018), New Delhi, India, 26- 28 September 2018. The full contents of the three supplements are available online at https:/bmcbioinformatics.biomedcentral.com/articles/supplements/volume-19- supplement-13, https://bmcgenomics.biomedcentral.com/articles/supplements/ volume-19-supplement-9 and https://bmcmedgenomics.biomedcentral.com/ articles/supplements/volume-11-supplement-7 [30-32].}

\section{Authors' contributions}

All authors have read and approved the final manuscript.

Ethics approval and consent to participate

Not applicable.

\section{Consent for publication}

Not applicable.

\section{Competing interests}

The authors declare that they have no competing interests.

\section{Publisher's Note}

Springer Nature remains neutral with regard to jurisdictional claims in published maps and institutional affiliations.

\section{Author details}

${ }^{1}$ School of Computational and Integrative Sciences, Jawaharlal Nehru University, New Delhi 110 067, India. ${ }^{2}$ Department of Biotechnology, Bhupat and Jyoti Mehta School of Biosciences, Indian Institute of Technology Madras, Chennai, Tamilnadu 600 036, India. ${ }^{3}$ Centre for Computational Biology, Indraprastha Institute of Information Technology, Okhla Industrial
Estate, Phase III, New Delhi 110020, India. ${ }^{4}$ Department of Biology, School of Science and Technology, Nazarbayev University, Astana, Kazakhstan. ${ }^{5}$ International Research Center for Medical Sciences, Graduate School of Medical Sciences, Kumamoto University, Kumamoto 860-0811, Japan. ${ }^{6}$ Department of Molecular Sciences, Macquarie University, Sydney, NSW 2109, Australia. ${ }^{7}$ Transformational Bioinformatics, Health and Biosecurity, Commonwealth Scientific and Industrial Research Organisation, Sydney, Australia.

Published: 18 April 2019

References

1. InCoB 2018. https://incob.apbionet.org/where-incob-has-been/. Accessed 25 Feb. 2019.

2. APBioNet ExCo Position Appointments. https://www.apbionet.org/apbionetexco-position-appointments/. Accessed 12 Mar 2019.

3. Bharti DR, Hemrom AJ, Lynn AM. GCAC: galaxy workflow system for predictive model building for virtual screening. BMC Bioinformatics. 2019; 19(Suppl 13):550.

4. Zheng Y, Peng H, Ghosh S, Lan C, Li J. Inverse similarity and reliable negative samples for drug side-effect prediction. BMC Bioinformatics. 2019; 19(Suppl 13):554.

5. Pritam M, Singh G, Swaroop S, Singh AK, Singh SP. Exploitation of reverse vaccinology and immunoinformatics as promising platform for genomewide screening of new effective vaccine candidates against Plasmodium falciparum. BMC Bioinformatics. 2019:19(Suppl 13):468.

6. Simon C, Davidsen K, Hansen C, Seymour E, Barnkob MB, Olsen LR. BioReader: a text mining tool for performing classification of biomedical literature. BMC Bioinformatics. 2019;19(Suppl 13):57.

7. Nor NAM, Taib NA, Saad M, Zaini HS, Ahmad Z, Ahmad Y, Dhillon SK. Development of electronic medical records for clinical and research purposes: the breast cancer module using an implementation framework in a middle income country- Malaysia. BMC Bioinformatics. 2019;19(Suppl 13):402.

8. Abu A, Guan NC, Hassan NIAA, Othman SA. Automated craniofacial landmarks detection on 3D image using geometry characteristics information. BMC Bioinformatics. 2019;19(Suppl 13):548.

9. Yang LA, Chang YJ, Chen SH, Lin CY, Ho JM. SQUAT: a sequencing quality assessment tool for data quality assessments of genome assemblies. BMC Genomics. 2019:12864-19-S9. https://doi.org/10.1186/s12864-019-5445-3.

10. Mat-Sharani S, Mohd Firdaus-Raih M. Computational discovery and annotation of conserved small open reading frames in fungal genomes. BMC Bioinformatics. 2019;19(Suppl 13):551.

11. Sharma A, Lysenko A, Lopez Y, Dehzangi A, Sharma R, Reddy H, Sattar A, Tsunoda T. HseSUMO: Sumoylation site prediction using half-sphere exposures of amino acids residues. BMC Genomics. 2019;12864-19-59. https://doi.org/10.1186/s12864-018-5206-8.

12. Sharma A, Chandra A. EvolStruct-Phogly: incorporating structural properties and evolutionary information from profile bigrams for the phosphoglycerylation prediction. BMC Genomics. 2019;12864-19-S9. https:// doi.org/10.1186/s12864-018-5383-5.

13. Reddy HM, Sharma A, Dehzangi A, Shigemizu D, Chandra AATT. GlyStruct: glycation prediction using structural properties of amino acid residues. BMC Bioinformatics. 2019;19(Suppl 13):547.

14. Huang KY, Kao HJ, Hsu JBK, Weng SL, Lee TY. Characterization and identification of lysine glutarylation based on intrinsic interdependence between positions in the substrate sites. BMC Bioinformatics. 2019; 19(Suppl 13):384

15. Sharma R, Sharma A, Patil A, Tsunoda T. Discovering MoRFs by trisecting intrinsically disordered protein sequence into terminals and middle regions. BMC Bioinformatics. 2019:19(Suppl 13):378.

16. Candido S, Palumbo GAP, Pennisi M, Russo G, Sgroi G, Di Salvatore V, Libra M, Pappalardo M. EpiMethEx: a tool for large-scale integrated analysis in methylation hotspots linked to genetic regulation. BMC Bioinformatics. 2019;19(Suppl 13):385

17. Jayasundara D, Saeed I, Herath D, Yang CY, Senanayake D, Sun Y, Chang BC, Tang SL, Halgamuge SK. ENVirT: inference of ecological characteristics of viruses from metagenomic data. BMC Bioinformatics. 2019;19(Suppl 13):377.

18. Hsu JBK, Chang TH, Lee GA, Lee TY. Identification of potential biomarkers related to glioma survival by gene expression profile analysis. BMC Med Genet. 2019;12920-11-S7. https://doi.org/10.1186/s12920-019-0479-6. 
19. Kumar R, Nagpal G, Kumar V, Salman SU, Agrawal P, Raghava GPS. HumCFS: a database of fragile sites in human chromosomes. BMC Genomics. 2019; 12864-19-S9. https://doi.org/10.1186/s12864-018-5330-5.

20. Guo J, Wang Q, Liu L, Ren S, Li S, Liao P, Zhao Z, Lu C, Jiang B, Sunkar R, Zheng $Y$. Analysis of microRNAs, phased small interfering RNAs and their potential targets in Rosa rugosa Thunb. BMC Genomics. 2019;12864-19-S9. https://doi.org/10.1186/s12864-018-5325-2.

21. Taguchi YH. Drug candidate identification based on gene expression of treated cells using tensor decomposition-based unsupervised feature extraction for large-scale data. BMC Bioinformatics. 2019;385,19(Suppl 13):388.

22. Nagai LAE, Sung-Joon Park SJ, Nakai K. Analyzing the 3D chromatin organization coordinating with gene expression regulation in B-cell lymphoma. BMC Med Genet. 2019;12920-11-S7. https://doi.org/10.1186/s12920-018-0437-8.

23. Hardianto A, Khanna V, Liu F, Ranganathan S. Diverse dynamics features of novel protein kinase $C$ (PKC) isozymes determine the selectivity of a fluorinated balanol analogue for PKCE. BMC Bioinformatics. 2019;19(Suppl 13):342.

24. Borah SM, Jha AN. Identification and analysis of structurally critical fragments in HopS2. BMC Bioinformatics. 2019;19(Suppl 13):552.

25. Agrawal P, Singh H, Srivastava HK, Singh S, Kishore G, Raghava GPS. Benchmarking of different molecular docking methods for protein-peptide docking. BMC Bioinformatics. 2019:19(Suppl 13):426.

26. Difli W, Puig J, Dispot A, Elati M. Latent network-based representations for large-scale gene expression data analysis. BMC Bioinformatics. 2019;19(Suppl 13):466.

27. Manoj VM, Anunanthini P, Clarancia PS, Dharshini S, Narayan JA Manickavasagam M, Sathishkumar R, Suresha GS, Hemaprabha G, Ram B, Appunu C. Comparative analysis of glyoxalase pathway genes in Erianthus arundinaceus and commercial sugarcane hybrid under salinity and drought conditions. BMC Genomics. 2019;12864-19-S9. https://doi.org/10.1186/ s12864-018-5349-7.

28. Sen S, Dey A, Chowdhury S, Maulik U, Chattopadhyay K. Understanding the evolutionary trend of intrinsically structural disorders in cancer relevant proteins as probed by Shannon entropy scoring and structure network analysis. BMC Bioinformatics. 2019:19(Suppl 13):549.

29. Kaalia R, Rajapakse JC. Functional homogeneity and specificity of topological modules in human proteome. BMC Bioinformatics. 2019; 19(Suppl 13):553.

30. 17th International Conference on Bioinformatics (InCoB 2018): bioinformatics. https://bmcbioinformatics.biomedcentral.com/articles/ supplements/volume-19-supplement-13 Accessed 1 March, 2019.

31. 17th International Conference on Bioinformatics (InCoB 2018): genomics. https://bmcgenomics.biomedcentral.com/articles/supplements/volume-19supplement-9 Accessed 1 March, 2019.

32. 17th International Conference on Bioinformatics (InCoB 2018): medical genomics. https://bmcmedgenomics.biomedcentral.com/articles/ supplements/volume-11-supplement-7 Accessed 1 March, 2019.

Ready to submit your research? Choose BMC and benefit from:

- fast, convenient online submission

- thorough peer review by experienced researchers in your field

- rapid publication on acceptance

- support for research data, including large and complex data types

- gold Open Access which fosters wider collaboration and increased citations

- maximum visibility for your research: over $100 \mathrm{M}$ website views per year

At $\mathrm{BMC}$, research is always in progress.

Learn more biomedcentral.com/submissions 